\title{
Impact of Practical Skill Demonstration on Internship Training During Community Medicine Posting- A Pilot Study
}

\author{
Puneet Gambhir ${ }^{1}$, Virender Verma ${ }^{2}$, Amarjit Singh ${ }^{3}$ \\ ${ }^{1}$ AssistantProfessor, Department of Community Medicine, Government Medical College and Rajindra Hospital, \\ Patiala (Punjab) India \\ ${ }^{2}$ Assistant Professor, Department of Community Medicine, Government Medical College and Rajindra Hospital, \\ Patiala (Punjab) India \\ ${ }^{3}$ Professor and Head, Department of Community Medicine, Government Medical College and Rajindra \\ Hospital, Patiala (Punjab) India
}

\begin{abstract}
Internship training is the backbone of undergraduate skill acquisition. Due to the lack of uniformity and a structured internship programme the competencies and skills acquired under graduation are lost during internship. In an attempt to formulate a broad-based structured internship programme this Pilot study will attempt to study the issue of skill refinement and its assessment. The Study was an ethical committee approved client consented case control study which enrolled interns posted in Rural Health Training Centre.4 basic competencies were considered. There was significant improvement in practical skills whereas the difference in gain in theoretical knowledge of test and skills remained non-significant.
\end{abstract}

Keywords: Internship training, core competencies, Practical skill demonstration

\section{Introduction}

Internship training is the backbone of undergraduate skill acquisition. The technical knowhow and competencies acquired during undergraduate studies are put to field practice and skills are refined for producing quality doctors. But due to the lack of uniformity and a structured internship programme the competencies and skills acquired during under-graduation are lost during internship.

In an attempt to formulate a broad-based structured internship programme this study will attempt to study the issue of skill refinement and its assessment. In other words, the purpose of the study is to understand the impact on internship programme of practical skill demonstration sessions. It will include a structured approach for basic skill development; involving practical skill demonstration, pre-test, videos, focussed group discussions, briefing, post- test and post-duty assessment through DOE (Directly Observed Evaluation)/ DOPS (Direct Observation of Procedural Skills).

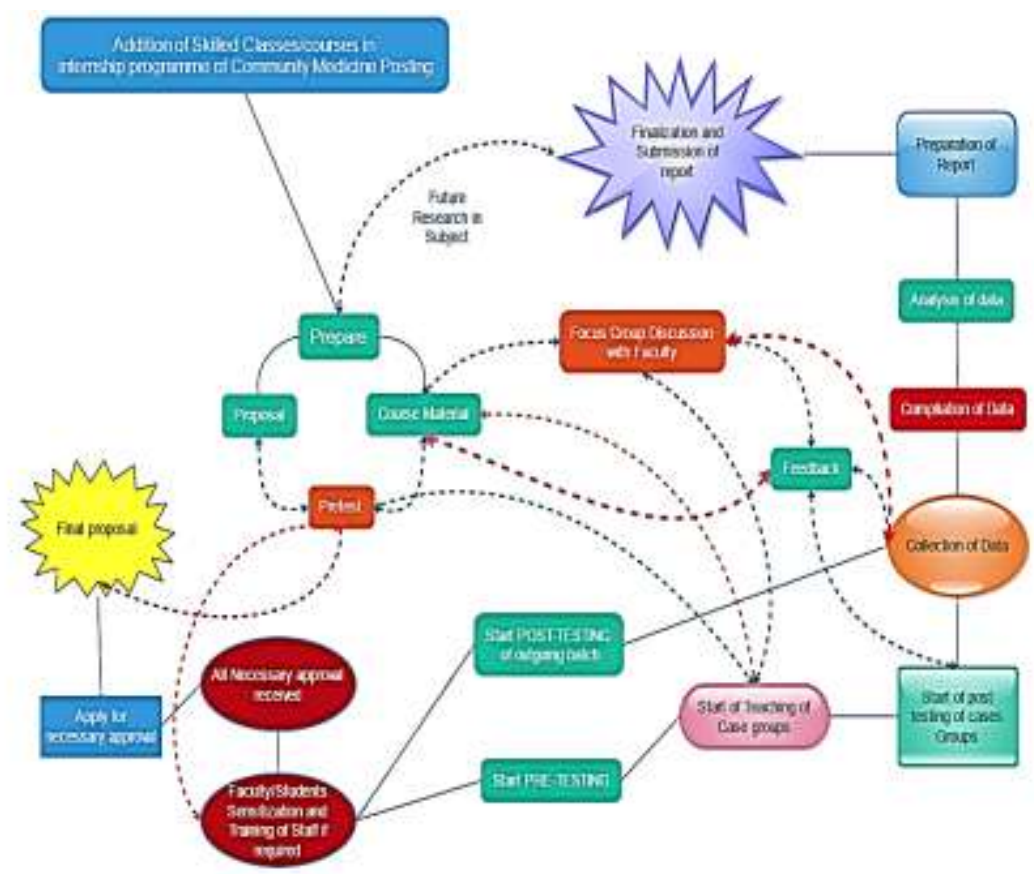

Figure 1: Concept Map for the study. 


\section{Material and Methods}

Aims\& Objectives: Optimize the basic competencies of interns through a structured format involving basic skill demonstration and evaluation

Setting: Study has been conducted with the interns posted in Rural Health Training Centre (Bhadson) under the Department of Community Medicine, Government Medical College Patiala.

Subjects: The interns presently undergoing internship programme. The interns who were posted in the community medicine department during the study period as first batch in present format and pre-demonstration interns in formatted internship were selected as controls for respective indicators while those who were posted as second batch were put under structured format during the study period; constituted the case group.

Methodology: The interns presently undergoing internship programme in present format were evaluated under the study. The following basic core competencies will be studied:

1. Measurement of Blood pressure

2. E.C.G interpretation

3. Staining and examination of slides especially Malaria and Tuberculosis

4. Measurement of haemoglobin

Both groups were evaluated by pretest, posttest and DOE/ DOPS in the above core competencies (to compare competencies at start and end of training). The second batch of all interns during the study period underwent structured practical skill demonstration in the above core competencies preceded by a pretest /DOE/ DOPS to evaluate previous acquired skills in the first two days of training. This was followed by daily briefing and twice a week training sessions. After completion of the duty the interns were assessed through post-test and DOE/ DOPS (Direct Observation of Procedural Skills). The short-term indicators were studied in the pilot study (Figure 2).

\begin{tabular}{|c|c|c|c|}
\hline S.no & $\begin{array}{l}\text { Outcome } \\
\text { Expected }\end{array}$ & Indicator & Data Collection Method \\
\hline \multirow[t]{4}{*}{1} & \multirow{4}{*}{ 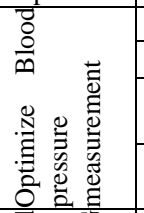 } & $\%$ change in interns taking proper Blood pressure (BP) & DOPS/ DOE pre-and post-test \\
\hline & & $\%$ change in interns having knowledge of proper BP measuring procedure & Pre-test and Post test \\
\hline & & $\begin{array}{l}\% \text { difference in taking proper } \mathrm{BP} \text { with interns taught by previous } \\
\text { curriculum }\end{array}$ & Pretest \&Post test \\
\hline & & $\begin{array}{l}\% \text { difference in knowledge of proper blood Pressure measuring procedure } \\
\text { with interns taught by previous curriculum }\end{array}$ & DOPS/DOE Pre-and post test \\
\hline \multirow[t]{4}{*}{2} & \multirow{4}{*}{ 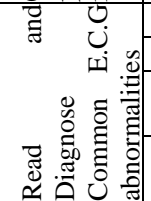 } & $\%$ change in interns reading proper ECG & DOPS/DOE pretest and post test \\
\hline & & $\%$ change in interns having knowledge of reading ECG & Pre-test and Post test \\
\hline & & $\begin{array}{l}\% \text { difference in reading proper ECG with interns taught by previous } \\
\text { curriculum }\end{array}$ & Pre and Post test \\
\hline & & $\begin{array}{l}\% \text { difference in knowledge of reading proper ECG with interns taught by } \\
\text { previous curriculum }\end{array}$ & DOPS/DOE Pre and post test \\
\hline \multirow[t]{6}{*}{3} & \multirow{6}{*}{ 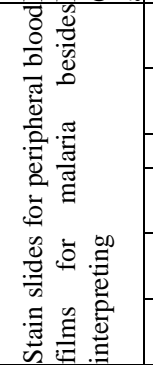 } & $\begin{array}{l}\text { \% change in interns proper Stain slides for peripheral blood films for } \\
\text { malaria }\end{array}$ & DOPS/DOE pretest and post test \\
\hline & & $\begin{array}{l}\% \text { change in interns properly interpretate slides for peripheral blood films } \\
\text { for malaria }\end{array}$ & DOPS/DOE pretest and post test \\
\hline & & $\%$ change in interns having knowledge of staining slides & Pre-test and Post test \\
\hline & & $\begin{array}{l}\% \text { difference in properly Staining slides for peripheral blood films for } \\
\text { malaria with interns taught by previous curriculum }\end{array}$ & Pre and Post test \\
\hline & & $\begin{array}{l}\text { \% difference in properly interpretate slides for peripheral blood films for } \\
\text { malaria with interns taught by previous curriculum }\end{array}$ & Pre and Post test \\
\hline & & $\begin{array}{l}\% \text { difference in knowledge of staining slides with interns taught by previous } \\
\text { curriculum }\end{array}$ & DOPS/DOE pre and post test \\
\hline \multirow[t]{6}{*}{4} & \multirow{6}{*}{ 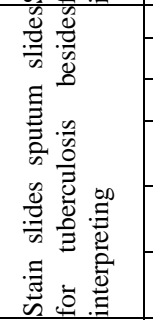 } & $\%$ change in interns proper Stain slides for Tuberculosis & DOPS/DOE pretest and post test \\
\hline & & $\%$ change in interns who properly interpret slides for Tuberculosis & DOPS/DOE pretest and post test \\
\hline & & $\%$ change in interns having knowledge of staining slides & Pre-test and Post test \\
\hline & & $\begin{array}{l}\text { \% difference in properly Staining slides for Tuberculosis with interns taught } \\
\text { by previous curriculum }\end{array}$ & Pre and Post test \\
\hline & & $\begin{array}{l}\% \text { difference in properly interpreted slides for Tuberculosis with interns } \\
\text { taught by previous curriculum }\end{array}$ & Pre and Post test \\
\hline & & $\begin{array}{l}\% \text { difference in knowledge of staining slides with interns taught by previous } \\
\text { curriculum }\end{array}$ & DOPS/DOE pre and post test \\
\hline \multirow[t]{4}{*}{5} & \multirow{4}{*}{ 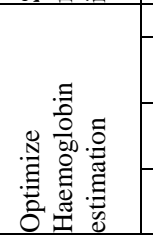 } & $\%$ change in interns who properly measure Haemoglobin & DOPS/DOE pre and post test \\
\hline & & $\begin{array}{l}\% \text { change in interns having knowledge of Proper Haemoglobin measuring } \\
\text { procedure }\end{array}$ & Pre-test and Post test \\
\hline & & $\begin{array}{l}\% \text { difference in proper measurement of Haemoglobin with interns taught by } \\
\text { previous curriculum }\end{array}$ & Pre and Post test \\
\hline & & $\begin{array}{l}\% \text { difference in knowledge of Proper measurement of Haemoglobin } \\
\text { procedure with interns taught by previous curriculum }\end{array}$ & DOPS/DOE pre and post test \\
\hline
\end{tabular}

Figure 2: Short Term Indicators for the Pilot Study. 
The interns scoring more than $60 \%$ in the structured evaluation were having minimum adequate knowledge and skill for the competency. The $60 \%$ (First division) cutoff was considered as number of interns gaining competency skills was considered as outcome rather than the average gain in knowledge and skills of individual interns. The results obtained were analyzed using Microsoft excel 2016 software and Epi info by CDC USA.

\section{Observations}

The present study was carried out on a study group of 30 each for cases and controls in the months of January and February. Criteria for inclusion of interns was as given in material and methods. The interns with the prior curriculum (controls) and under the study curriculum (case- subjects) showed no significant differences in the percentage of adequate knowledge and skills of pretest of the various competencies.

\begin{tabular}{|c|c|c|c|c|c|c|c|c|c|}
\hline \multirow{2}{*}{ S.no } & \multirow{2}{*}{$\begin{array}{l}\text { Outcome } \\
\text { Expected }\end{array}$} & \multirow{2}{*}{ Competency Aspect } & \multicolumn{3}{|c|}{$\begin{array}{l}\text { Interns with the prior } \\
\text { curriculum (30) (Controls) }\end{array}$} & \multicolumn{3}{|c|}{$\begin{array}{l}\text { Interns under the study } \\
\text { curriculum (30) (Case } \\
\text { Subjects) }\end{array}$} & \multirow{2}{*}{$\begin{array}{l}\text { Overall } \\
\text { Difference } \\
\text { in groups } \\
\text { after post } \\
\text { test }\end{array}$} \\
\hline & & & Pretest & $\begin{array}{l}\text { Post } \\
\text { test }\end{array}$ & Difference & Pretest & $\begin{array}{l}\text { Post } \\
\text { test }\end{array}$ & Difference & \\
\hline \multirow{2}{*}{1} & \multirow{2}{*}{ 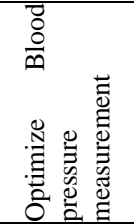 } & $\begin{array}{l}\text { Taking proper Blood } \\
\text { pressure }(\mathrm{BP})\end{array}$ & 33.3 & 40.3 & 7 & 26.7 & 86.7 & 60 & 46.4 \\
\hline & & $\begin{array}{l}\text { Interns having } \\
\text { knowledge of proper BP } \\
\text { measuring procedure }\end{array}$ & 76.7 & 93.3 & 16.6 & 80 & 100 & 20 & 6.7 \\
\hline \multirow[b]{2}{*}{2} & \multirow{2}{*}{ 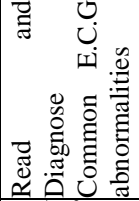 } & $\begin{array}{l}\text { Interns reading proper } \\
\text { ECG }\end{array}$ & 24 & 30 & 6 & 24 & 60 & 36 & 30 \\
\hline & & $\begin{array}{l}\text { Interns } \\
\text { knowledge of reading } \\
\text { ECG }\end{array}$ & 63.3 & 86.7 & 23.4 & 70 & 90.3 & 20.3 & 3.6 \\
\hline \multirow{3}{*}{3} & \multirow{3}{*}{ 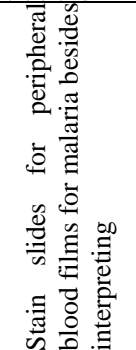 } & $\begin{array}{l}\text { Interns proper Stain } \\
\text { slides for peripheral } \\
\text { blood films for malaria }\end{array}$ & 13.3 & 26.7 & 13.4 & 13.3 & 56.7 & 43.4 & 30 \\
\hline & & $\begin{array}{lr}\text { Interns } & \text { properly } \\
\text { interpretate slides for } \\
\text { peripheral blood films } \\
\text { for malaria }\end{array}$ & 46.7 & 63.4 & 16.7 & 50 & 90 & 40 & 26.6 \\
\hline & & $\begin{array}{l}\text { Interns } \\
\text { knowledge of } \quad \text { staining } \\
\text { slides }\end{array}$ & 70 & 90 & 20 & 80 & 96.7 & 16.7 & 6.7 \\
\hline \multirow{3}{*}{4} & \multirow{3}{*}{ 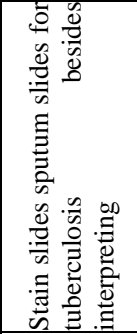 } & $\begin{array}{l}\text { Interns proper Stain } \\
\text { slides for Tuberculosis }\end{array}$ & 20 & 26.7 & 6.7 & 20 & 63.3 & 43.3 & 36.6 \\
\hline & & $\begin{array}{l}\text { Interns who properly } \\
\text { interpret slides for } \\
\text { Tuberculosis }\end{array}$ & 40 & 50 & 10 & 50 & 93.3 & 43.3 & 43.3 \\
\hline & & $\begin{array}{l}\text { Interns } \\
\text { knowledge of } \begin{array}{r}\text { having } \\
\text { staining }\end{array}\end{array}$ & 70 & 90 & 20 & 80 & 96.7 & 16.7 & 6.7 \\
\hline \multirow[b]{2}{*}{5} & \multirow[b]{2}{*}{ 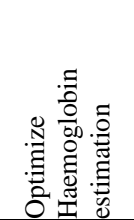 } & $\begin{array}{l}\text { Interns who properly } \\
\text { measure Haemoglobin }\end{array}$ & 40 & 63.4 & 23.4 & 33.3 & 90 & 56.7 & 26.6 \\
\hline & & $\begin{array}{l}\text { Interns having } \\
\text { knowledge of Proper } \\
\text { Haemoglobin measuring } \\
\text { procedure }\end{array}$ & 70 & 73.3 & 3.3 & 63.3 & 93.3 & 30 & 20 \\
\hline
\end{tabular}

Figure 3: Table showing percentages of interns having adequate minimum knowledge and skills i.e. $60 \%$ of evaluated score in the concerned competency.

The knowledge acquired during their MBBS course had a significant influence on the pretest results. Lack of practical training in pre-internship training was clearly reflected in lack of procedural skills in various competencies. The $\%$ of students who could take blood pressure properly one of the basics was between 26.7 to $33.3 \%$ only. The controls showed an increase of $7 \%$ in skills as to $60 \%$ by cases. Although difference gain in knowledge showed not as marked in skills (cases $16.6 \%$ and controls $20 \%$ ). 


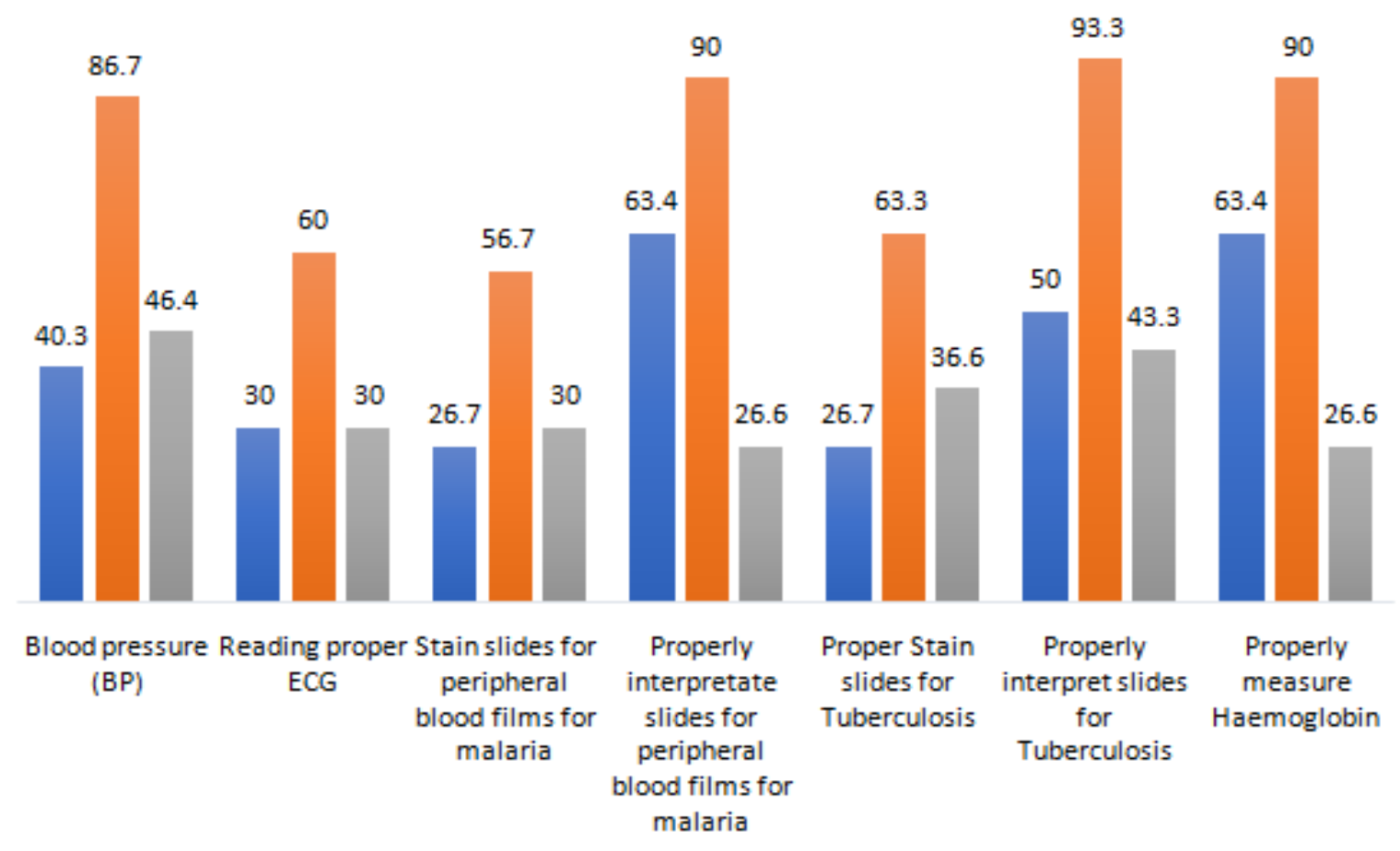

- Interns with the prior curriculum

= Interns under the study curriculum

- Overall Difference in groups after post test

Figure 4: Bar Diagram showing differences in practical skills of the two groups. (data shown in percentages)

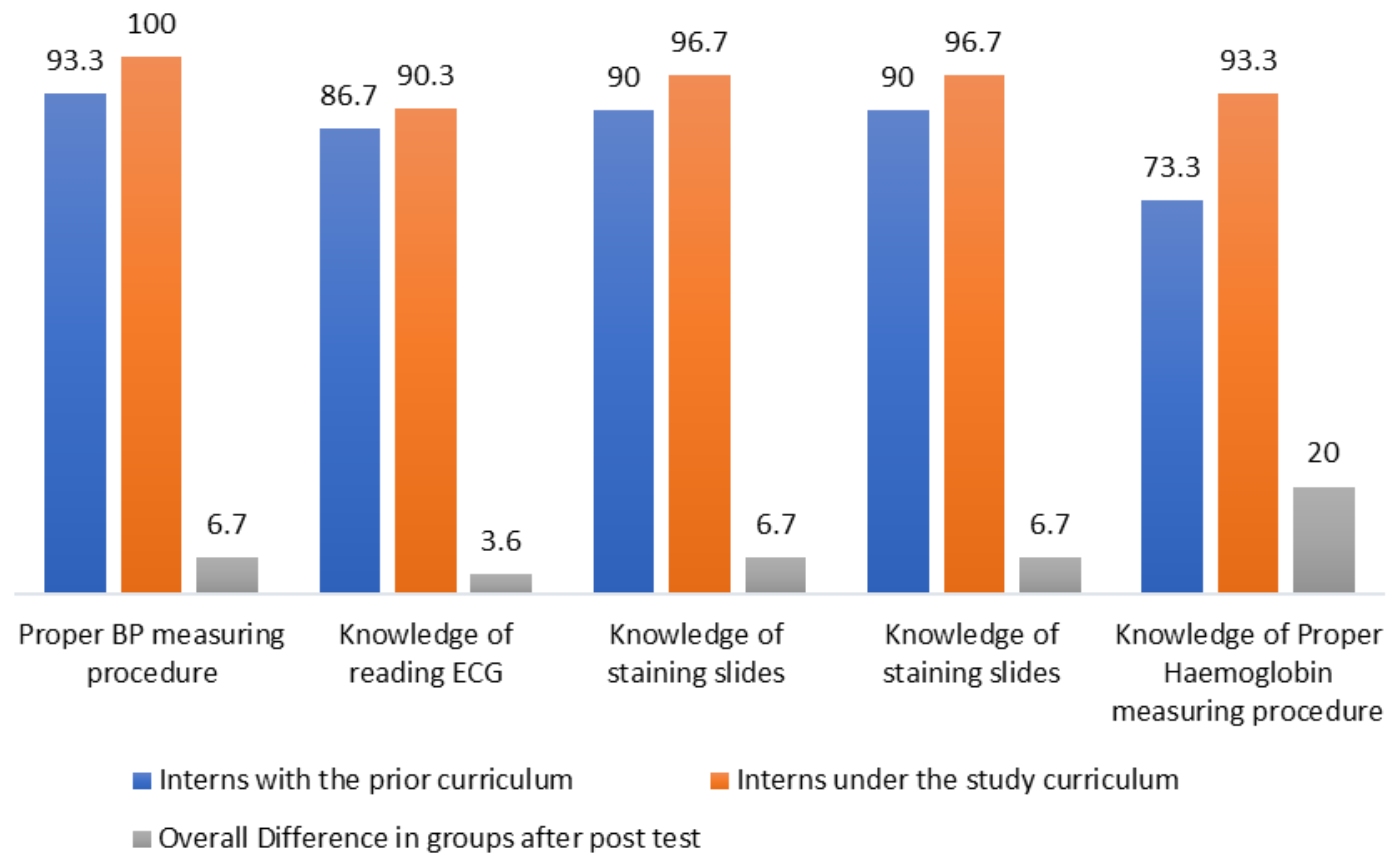

Figure 4: Bar Diagram showing differences in Knowledge of the two groups. (data shown in percentages)

A similar trend was observed in ECG interpretation (for skills- cases 6\% and controls 36\%; for knowledge - cases $23.4 \%$ and controls- 20.3\%), PBF for malaria slides (for skills staining- cases $13.3 \%$ and controls 56.7\%; interpretation- cases $16.7 \%$ and controls $40 \%$; for knowledge - cases $20 \%$ and controls$16.3 \%$ ),Sputum slides for tuberculosis (for skills staining- cases $6.7 \%$ and controls $43.3 \%$; interpretation- cases 
$10 \%$ and controls $43.3 \%$; for knowledge - cases $20 \%$ and controls- $16.7 \%$ ) and $\mathrm{Hb}$ estimation (for skills- cases $23.4 \%$ and controls $56.7 \%$ ).

\section{Discussion}

Competency-based medical education (CBME) is gaining momentum across the globe. The Medical Council of India has described the basic competencies required of an Indian Medical Graduate and designed a competency-based module on attitudes and communication. Widespread adoption of a competency-based approach would mean a paradigm shift in the current approach to medical education. The competency issue among medical graduate has been a matter of concern for teaching faculty and regulatory authorities of the country.(1)The MCI has been intent in gently moving toward a competency-based curriculum as described in its Vision 2015 document.(2)To implement the system the regulators have been attempting various models for implementation in various institutes. This study was the second pilot study done in this field by the same team and among the few being done in rural health training centres. Hence there were not many references for comparison of data.

Form the results it was very evident that although knowledge among the number of interns was reasonably good but the skills were highly wanted for. The skills which are taught in basic years of MBBS training are not repeated through the curriculum and the students are expected to emulate them in field conditions. To overcome this deficiency if we could provide structured internship training programme with proactive training and evaluation programme, we may be able to introduce some competencies to the medical graduates till the curriculum is revised. This pilot study is an attempt to design such protocol and study the effect of such interventions. Taking four basic skills this study has shown that such interventions and proactive approach may be productive in attaining the desired competencies. The study demonstrated a marked increase in the number of interns with desired skills. Although in doing so, the students had briefing sessions on daily basis and teaching sessions twice a week.

But some issues have been brought up during the study; for example, both the groups had their first posting in Community Medicine Department, hence what will be the effect of other departments on the basic skills and knowledges; how much the knowledge and skills they will retain/ improve at end of internship programme; the students' mindset for attending these sessions in the later of the year near their PG entrance examination, the increase in workload, feasibility of such briefing and training sessions in other departments etc. are issues to be studied. (Parameters included in follow up study)

\section{Conclusion}

There was marked improvement in practical skills in the interns who had undergone practical session training during the study.

The practical skill demonstrations definitely improve the competency and outcome of Internship training.

\section{Acknowledgements}

The authors are highly indebted to Dr Tejinder Singh and his emeritus team of experts from FIME, Christian Medical College, Ludhiana, Punjab, India for their support and expert opinion during formulation/ designing of the First pilot study on the basis of which this study was made possible.

\section{Declarations}

a. Funding: Nil

b. Conflict of interest: Nil

c. Ethical approval: Approved

\section{References}

[1]. Nilima Shah Chetna Desai, Gokul Jorwekar, Dinesh Badyal, Tejinder Singh Competency-based medical education: An overview and application in pharmacology. Indian Journal of Pharmacology. 2016; Oct; 48 (Suppl. 1): S5-S9.

[2]. MCI India; MCI. Vision 2015. MCI New Delhi 2011; http://www.mciindia.org/tools/announcement/MCI booklet.pdf

[3]. Morris A, Hewitt J, Roberts C. Practical experience of using directly observed procedures, mini clinical evaluation examinations, and peer observation in pre-registration house officer (FY1) trainees. Postgraduate Medical Journal 2006; 82:285-88.

[4]. Wilkinson J, Benjamin A, Wade W. assessing the performance of doctors in training. BMJ 2003; 327: s91-2.

[5]. Sidhu R, Grober E, Musselman L, Reznick R. Assessing competency in surgery: Where to begin? Surgery 2004; 135(1):6-20. 